\title{
Analisis Rasio Prestasi Manajemen Irigasi pada Budidaya Tanaman Padi di Subak Kabupaten
} Tabanan

\section{Analysis of Irrigation Management Achievement Ratio in Rice Cultivation in Tabanan Subak Regency}

\section{Kadek Arya Santika, I Wayan Tika*, I Putu Gede Budisanjaya}

Program Studi Teknik Pertanian, Fakultas Teknologi Pertanian Universitas Udayana, Badung, Bali, Indonesia *email: wayantikaftp@gmail.com

\begin{abstract}
Sistem subak adalah merupakan salah satu bentuk sistem irigasi yang mampu mengakomodasikan dinamika sistem sosio-teknis masyarakat setempat. Air irigasi dikelola dengan prinsip-prinsip keadilan, keterbukaan, harmoni dan kebersamaan, melalui suatu organisasi yang fleksibel yang sesuai dengan kepentingan masyarakat. Sistem irigasi erat kaitannya tentang pemberian air irigasi pada tanaman budidaya tanaman padi. Salah satu aspek yang akan dinilai dalam sistem irigasi adalah Rasio Prestasi Manajemen (RPM) irigasi Tujuan penelitian ini adalah untuk mengetahui klasifikasi RPM di suatu subak. Perolehan data primer dilakukan dengan metode wawancara, pengamatan secara langsung dan pengukuran sedangkan data sekunder diperoleh dari BMKG Wilayah III Denpasar. Data yang telah dikumpulkan selanjutnya akan dianalisis menggunakan metode Rasio Prestasi Manajemen (RPM) Irigasi. RPM irigasi setiap subak dinilai dengan menggunakan empat rentang nilai yaitu Baik bila $0.75<\mathrm{RPM}<1.25$, Cukup bila $0.60<\mathrm{RPM}<$ 0.75 atau $1.25<\mathrm{RPM}<1.40$, Kurang $0.40<\mathrm{RPM}<0.60$ atau $1.40<\mathrm{RPM}<1.60$ dan Sangat kurang bila $\mathrm{RPM}<0.40$ atau RPM $>1.60$ Hasil metode analisis rasio prestasi manajemen irigasi pada budidaya tanaman padi diperoleh RPM daerah hulu dari periode I sampai VII rasio prestasi manajemen irigasinya dengan nilai rata-rata 3.35 (Sangat Kurang) dan untuk daerah tengah RPM irigasi dari periode I sampai V nilai rata-ratanya 1.78 (Sangat Kurang), periode VI dengan nilai 1.56 (Kurang), periode VII dengan nilai 1.03 (Baik) sedangkan untuk subak daerah hilir diperoleh RPM irigasinya dari periode I sampai III dengan nilai rata-rata 2.25 (Sangat Kurang) dan untuk periode IV sampai VII dengan nilai rata-rata 0.92 (Baik).
\end{abstract}

Kata kunci: Subak, irigasi, budidaya tanaman padi, analisis RPM.

Subak system is one form of irrigation system that is able to accommodate the dynamics of the sociotechnical system of the local community. Irrigation water is managed with the principles of justice, openness, harmony and togetherness, through a flexible organization that is in accordance with the interests of the community. Irrigation systems are closely related to the provision of irrigation water to rice cultivation plants. One aspect that will be assessed in an irrigation system is the Irrigation Management Performance Ratio (MPR). The purpose of this study is to determine the MPR classification in a subak by scoring in each MPR classification. The primary data was collected by interview, direct observation and measurement methods while secondary data was obtained from BMKG Region III Denpasar. The data that has been collected will then be rated and analyzed. Irrigation MPR for each subak is assessed using four ranges of values: Good if $0.75<$ MPR $<1.25$, Sufficient if $0.60<$ MPR $<0.75$ or $1.25<$ MPR $<1.40$, Less 0.40 $<$ MPR $<0.60$ or $1.40<$ MPR $<1.60$ and Very less if MPR $<0.40$ or MPR $>1.60$. The results of the analysis method of irrigation management achievement ratio in the cultivation of rice obtained by the upstream area MPR from periods I to VII irrigation management achievement ratio with an average value of 10.05 (Very Less) and for the middle area of irrigation MPR from period I to V the average value is 1.78 (Very Less), period VI with a value of 1.56 (Less), period VII with a value of 1.03 (Good) while for the downstream subak the MPR was obtained from the I to III periods with an average value of 2.25 (Very Less) and for periods IV to VII with an average value of 0.92 (Good).

Keyword: Subak, irrigation, rice cultivation, MPR analysis

\section{PENDAHULUAN}

Sistem irigasi adalah satu kesatuan yang tersusun dari komponen, menyangkut upaya penyediaan, pembagian, pengelolaan dan pengaturan air irigasi untuk menunjang pertanian di suatu subak (Jannata, et al. 2015). Subak dalam mengelola air irigasi telah diakui keberhasilannya. Meskipun masih tradisional dan sederhana, namun justru kondisi demikian mampu menggerakkan kinerja anggotanya dalam menjaga bangunan jaringan irigasi agar tetap bagus guna meningkatkan produktivitas tanaman padi (Windia et.al, 2015). Dalam hal peningkatan 
produktivitas tanaman padi perlu adanya pengelolaan air.

Pengelolaan air berperan sangat penting menjadi salah satu kunci keberhasilan petani dalam meningkatan produktifitas padi di lahan sawah (Anonim, 2011). Produksi padi akan menurun jika pengelolaan air yang tidak tepat. Tanaman padi membutuhkan air yang volumenya berbeda setiap masa pertumbuhannya (Kusumowarno, 2014). Kebutuhan air irigasi tanaman padi meliputi kebutuhan air untuk evapotranspirasi, kehilangan air karena perkolasi dan rembesan disamping itu untuk pengairan awal dibutuhkan sejumlah air untuk penjenuhan (Vegara, 2002). Irigasi bagi tanaman padi diberikan dengan cara penggenangan bertujuan sebagai penyedia air yang cukup dan stabil untuk menjamin produksi padi. Namun pada kenyataannya atau di lapangan petani masih belum memahami dalam pengelolaan air sehingga mengakibatkan pemberian air yang berlebih dan pemberian air yang kurang, ini nantinya akan berdampak pada produksi padi yang menurun.

Sumber air irigasi pada subak umumnya dari sungai. Sungai Yeh Ho dan Yeh Sungi merupakan beberapa sungai yang dimanfaatkan air irigasinya untuk pertanian. Pemanfaatan sungai Yeh Ho sebagai air irigasi untuk subak bermula dari daerah irigasi subak Aya (hulu) sampai daerah irigasi subak Sungsang (hilir). Sedangkan untuk sungai Yeh Sungi, hulunya bermula di daerah irigasi subak Pama Palian dan sampai hilir di daerah irigasi subak Mundeh.

Tingkat pemberian air masih belum efisien dimasingmasing subak untuk siklus budidaya tanaman padi. Salah satu kasus pemberian yang belum efisien di suatu subak adalah dimana pada saat umur padi di periode VI dan VII mestinya air tidak terlalu banyak dberikan namun di lapangan ternyata diberikan air yang berlebih sehingga menyebabkan produktivitas tanaman padi menurun. Maka dari itu perlu adanya adanya klasifikasi Rasio Prestasi Manajemen (RPM) yang didefenisikan sebagai perbandingan antara debit aktual dengan debit yang diperlukan di berbagai pintu sadap selama periode operasional irigasi (Sugeng, 2015) yang bertujuan untuk mengetahui baik buruknya pemberian air irigasi selama siklus budidaya tanaman padi.

Pada perhitungan Rasio Prestasi Managemen (RPM), memiliki 4 klasifikasi nilai yang menjadi acuan baik tidaknya irigasi pada suatu jaringan irigasi maupun daerah irigasi. Jika nilai Nilai MPR $>1$ berarti air yang diberikan berlebihan, bila $<1$ air yang diberikan kurang. MPR yang konstan mendekati 1 di setiap pintu sadap tersier pada setiap periode budidaya tanaman padi. Tujuan dari penelitian ini mengetahui besar nilai klasifikasi rasio prestasi manajemen.

\section{METODE}

\section{Tempat dan Waktu Penelitian}

Lokasi penelitian dilakukan pada subak yang berada di Daerah Alirah Sungai Yeh Ho dan Yeh Sungi di Kabupaten Tabanan sebanyak 9 subak dan dibagi 3 kriteria hulu, tengah dan hilir mengikuti aliran sungai. Penelitian dilaksanakan pada bulan Januari 2019 sampai Juli 2019.

\section{Alat dan Bahan Penelitian}

Bahan dan alat yang digunakan dalam penelitian ini adalah beberapa yang dapat membantu untuk mengukur kedalaman air dan lebar ambang di saluran sekunder seperti, meteran, penggaris dan alat tulis. Untuk mengetahui kebutuhan air tanaman padi diperlukan data iklim, curah hujan dan untuk mengolah data sekunder di perlukan software CROPWAT 8.0,

\section{Pelaksanaan Penelitian}

Penelitian ini menggunakan pendekatan analisis kuantitatif dan melalui metode wawancara. Wawancara yang dimaksud meliputi data primer. Wawancara dilakukan pada pekaseh masing-masing subak untuk mengetahui luas lahan, umur padi dan nama subak. Pengukuran data primer untuk memperoleh debit air yang tersedia di bangunan bagi pada subak. Data sekunder berupa data iklim yang diperoleh dari BMKG Wilayah III Denpasar. Berdasarkan data iklim tersebut, dilakukan perhitungan untuk menentukan evapotranspirasi potensial dan curah hujan efektif

\section{Pengukuran Debit Tersedia}

Pengukuran debit tersedia dilakukan di bangunan bagi saluran inlet ke masing-masing subak yang berada di daerah hulu, tengah dan hilir dengan cara mengukur lebar ambang dan tinggi air di bangunan bagi (saluran sekunder). Pengukuran dilakukan setiap dua minggu sekali selama budidaya tanaman padi. Untuk titik pengukuran ada 9 yang tersebar dimasing - masing bangunan sadap di setiap subak.

\section{Analisis Kebutuhan Air Irigasi}

Perhitungan kebutuhan air irigasi dilakukan dengan bantuan Software CROPWAT 8.0. tahapan dan cara kerja yang dilaksanakan adalah sebagai berikut.

1. Evapotranspirasi Potensial, dalam perhitungan evapotranspirasi potensial menggunakan persamaan Penman dengan bantuan software CROPWAT 8.0, (Viessman, 2001). yang menggunakan data klimatologi. Data klimatologi yang dimasukan yaitu data rata- rata lima belas tahun terakhir dari tahun 2004 sampai dengan tahun 2018. Data iklim yang diambil bersumber dari Balai Besar Meteorologi Klimatologi dan Geofisika Wilayah III Denpasar. 
2. Curah Hujan Efektif, perhitungan curah hujan efektif dilakukan dengan bantuan software CROPWAT 8.0 yang menggunakan rumus Dependable rain (FAO/AGLW formula) (Sosrodarsono, 2003). Dalam perhitungan curah hujan efektif, data yang digunakan bersumber dari stasiun penakar hujan yang berlokasi di Desa Buruan dengan memasukan data rata-rata lima belas tahun terakhir dari tahun 2004 sampai dengan tahun 2018.

3. Kebutuhan Air Irigasi (KAI), berdasarkan perhitungan evapotranspirasi potensial (ETo), curah hujan efektif, koefisien tanaman $(\mathrm{Kc})$ berdasarkan umur padi dan perkolasi (P) selanjutnya memakai rumus :

$\mathrm{ETc}=\mathrm{ETo} \mathrm{x}$ Kc setelah didapat evapotranspirasi tanaman (ETc) selanjutnya memakai rumus: $\mathrm{KAI}=(\mathrm{ETc}+\mathrm{P}-\mathrm{Re})(\mathrm{Kalsim}, 2006)$.

\section{Analisis RPM}

Analisis Rasio Prestasi Manajemen Irigasi dilakukan dengan membandingkan debit yang tersedia (riil) dengan debit yang direncanakan dengan mengetahui luas subak sebanyak 9 subak dibagi kriteria subak hulu, tengah dan hilir. Untuk menganalisa data memakai analisis Management Performance Ratio dapat diterjemahkan menjadi RPM (rasio prestasi manajemen) irigasi memakai perhitungan sebagai berikut (Sugeng, 2015)

Management Performance Ratio

$=$

Debit Air tersedia

$\overline{\text { Debit Air yang diperlukan (KAI) }}$

[1]

Kemudian diklasifikasikan dengan beberapa nilai sebagai berikut:

- Baik bila $0.75<\mathrm{RPM}<1.25$,

- Cukup bila $0.60<\mathrm{RPM}<0.75$ atau $1.25<\mathrm{RPM}$ $<1.40$,

- Kurang $0.40<\mathrm{RPM}<0.60$ atau 1.40 $<$ RPM $<1.60$ dan

- Sangat kurang bila RPM $<0.40$ atau RPM $>1.60$.

Dengan rasio prestasi manajemen irigasi ini diharapkan dapat mengetahui baik buruknya pemberian air irigasi yang diterima oleh subak sesuai dengan kebutuhan air irigasi tanaman padi yang berpatokan pada umur padi.

\section{HASIL DAN PEMBAHASAN}

\section{Kebutuhan Air Irigasi pada Subak Daerah Hulu, Tengah dan Hilir}

Dari hasil perhitungan kebutuhan air irigasi pada subak di masing-masing daerah hulu, tengah dan hilir dapat dilihat pada Gambar 1. Untuk subak daerah hulu periode awal tanam pada bulan Januari sampai Februari dan untuk masa panen daerah hulu pada bulan April sampai Mei. Subak daerah tengah periode awal tanam pada bulan Februari dan masa panen pada bulan Mei. Sedangkan subak daerah hilir periode awal tanam pada bulan Maret dan masa panen pada bulan Juni.

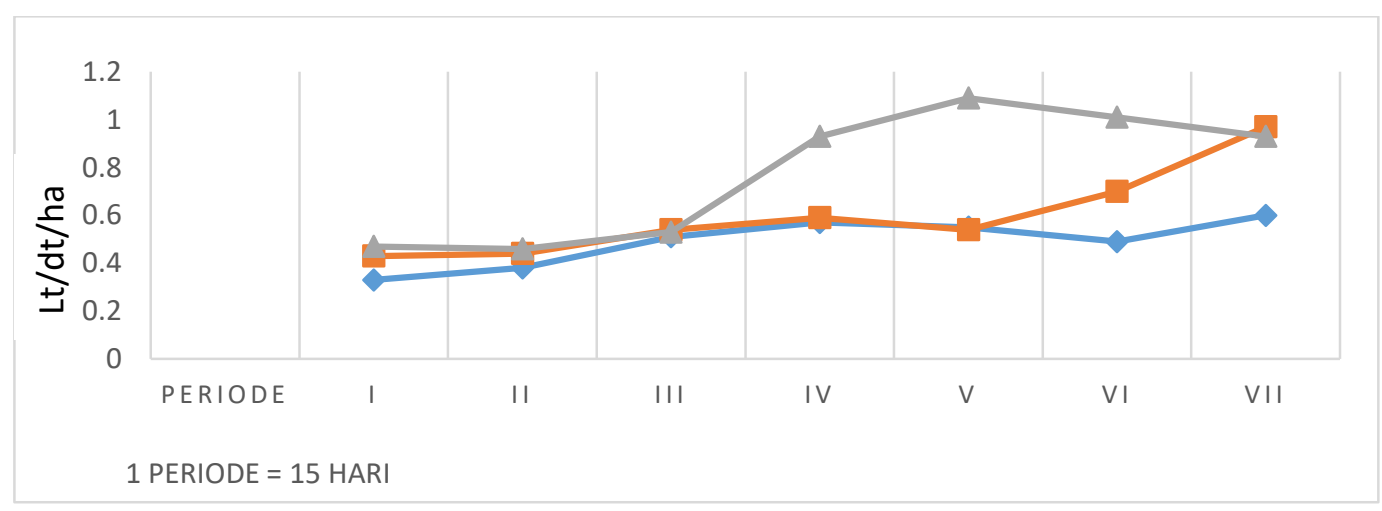

Gambar 1. Grafik Kebutuhan Air Irigasi Untuk Budidaya Tanaman Padi Daerah Hulu, Teng-ah dan Hilir Subak Kabupaten Tabanan

Gambar 1, menunjukan bahwa kebutuhan air irigasi rata-rata untuk budidaya tanaman padi daerah hulu cenderung sedikit $0.49 \mathrm{lt} / \mathrm{dt} / \mathrm{ha}$ dibandingkan dengan daerah tengah $0.60 \mathrm{lt} / \mathrm{dt} / \mathrm{ha}$ dan hilir $0.77 \mathrm{lt} / \mathrm{dt} / \mathrm{ha}$ ini disebabkan karena daerah hulu mempunyai curah hujan yang tinggi. Berdasarkan hasil perhitungan curah hujan efektif didapat, bahwa subak daerah hulu mempunyai curah hujan eketif $6 \mathrm{~mm} / \mathrm{hari}$ pada

periode budidaya tanaman padi. Curah hujan efektif sangat berpengaruh terhadap kebutuhan air irigasi, semakin besar curah hujan efektif yang dapat diserap oleh tanaman semakin sedikit kebutuhan air irigasi tanaman (Heryani, et.al, 2018). Dari hasil perhitungan Gambar 1 menunjukan grafik subak daerah hulu mengalami kenaikan dari periode I (bulan Januari) sampai IV (bulan Maret) kemudian turun 
diperiode V sampai VI (bulan April) dan naik lagi pada periode VII (bulan Mei). Pada Gambar 1 menunjukan periode VII subak daerah hulu mengalami kenaikan kebutuhan air irigasi maksimum ini dipengaruhi oleh curah hujan yang terjadi pada periode tersebut mengalami penurunan intensitas.

Subak daerah tengah mempunyai kebutuhan air irigasi rata-rata lebih tinggi $0.60 \mathrm{lt} / \mathrm{dt} / \mathrm{ha}$ dibandingkan dengan subak daerah hulu $0.49 \mathrm{lt} / \mathrm{dt} / \mathrm{ha}$ dapat dilihat pada Gambar 1. Ini dipengaruhi oleh perbedaan intensitas curah hujan yang terjadi di daerah hulu dan tengah. Berdasarkan hasil perhitungan curah hujan efektif didapat, bahwa subak daerah tengah mempunyai curah hujan efektif 4.85 $\mathrm{mm} /$ hari selama periode budidaya tanaman padi. Untuk curah hujan efektif $4.85 \mathrm{~mm} / \mathrm{hari}$ ini lebih rendah dari curah hujan efektif subak daerah hulu yaitu $6 \mathrm{~mm} /$ hari sehingga berdampak pada kebutuhan air irigasi. Periode VI dan VII (bulan Mei) merupakan puncak maksimal kebutuhan air irigasi subak daerah tengah ini disebabkan oleh menurunnya curah hujan menjadi $3.22 \mathrm{~mm} /$ hari pada periode tersebut. Sedangkan pada periode I sampai III (bulan Februari sampai Maret) justru merupakan titik terendah kebutuhan air irigasi seharusnya pada periode ini merupakan puncak kebutuhan air irigasi seperti yang dijelaskan oleh Subagyono et al. (2010) menyatakan pada fase vegetatif (periode I sampai III) kebutuhan air tanaman lebih banyak untuk tanaman padi karena dipengaruhi oleh koefisien tanaman dan evapotranspirasi tanaman yang tinggi, akan tetapi semua itu mampu dipenuhi oleh curah hujan efektif. Subak daerah hilir merupakan daerah yang paling tinggi kebutuhan air irigasinya yaitu $0.77 \mathrm{lt} / \mathrm{dt} / \mathrm{ha}$ dibandingkan subak daerah hulu dan tengah. Ini dipengaruhi oleh rendahnya curah hujan yang terjadi selama periode budidaya tanaman padi di daerah hilir. Berdasarkan hasil perhitungan curah hujan efektif didapat, curah hujan efektif yang yang terjadi selama masa tanam di daerah subak daerah hilir yaitu 3.19 $\mathrm{mm} /$ hari. Pada periode III sampai V (fase generatif) terjadi kebutuhan air irigasi maksimum sedangkan pada kebutuhan air irigasi minimum terjadi periode I. Menurut Sosrodarsono dan Takeda (2003), yang menyatakan bahwa kebutuhan air irigasi yang tinggi pada fase generatif tersebut dipengaruhi oleh banyaknya air yang menghilang yang disebabkan oleh tingginya evapotranspirasi potensial (ETo) dan rendahnya curah hujan efektif (Re). Apabila curah hujan efektif $(\mathrm{Re})$ rendah akan menyebabkan kebutuhan air irigasi yang diperlukan tinggi, sedangkan kebutuhan air irigasi dimasa generatif yang rendah itu disebabkan oleh curah hujan yang tinggi sehingga dapat menggantikan air yang hilang yang disebabkan oleh tingginya nilai evapotranspirasi potensial.

\section{Ketersediaan Air Irigasi Daerah Hulu, Tengah dan Hilir}

Dari hasil pengukuran ketersediaan air irigasi untuk budidaya tanaman padi yang dilakukan pada daerah hulu, tengah dan hilir dapat dilihat pada Gambar 2 . Untuk subak daerah hulu periode awal tanam pada bulan Januari sampai Februari dan untuk masa panen daerah hulu pada bulan April sampai Mei. Subak daerah tengah periode awal tanam pada bulan Februari dan masa panen pada bulan Mei. Sedangkan subak daerah hilir periode awal tanam pada bulan Maret dan masa panen pada bulan Juni.



Gambar 2. Ketersediaan Air Irigasi Untuk Budidaya Tanaman Padi Subak Daerah Hulu, Tengah dan Hilir Kabupaten Tabanan

Gambar 2, menunjukan bahwa adanya tingkat perbedaan ketersediaan air irigasi yang cukup besar. Di daerah hulu tingkat ketersediaan air irigasi ratarata jauh lebih besar $4.63 \mathrm{lt} / \mathrm{dt} / \mathrm{ha}$ cenderung suplai air irigasi lebih banyak dibandingkan lokasi tengah dan hilir. Kondisi dibagian tengah relative moderat, meskipun terdapat kecendrungan penggunaan air irigasi yang melebihi dari kebutuhan. 
Perbedaan ketersediaan air yang cukup besar antara ketiga lokasi berkaitan erat dengan kondisi air disaluran tersier (Gambar 2). Penyadapan air oleh petani di masing-masing lokasi tergantung dari ketersedian air di saluran tersier. Lokasi hulu merupakan daerah awal masuknya air ke saluran tersier, sehingga debit air irigasi yang tersedia di saluran cukup besar dan memicu petani untuk menyadap air secara berlebihan. Sampai ke lokasi tengah jumlah air telah berkurang, sehingga air masuk ke petakan juga tidak sebanyak dilokasi hulu. Sedangkan areal persawahan dilokasi hilir memperoleh sisa air yang sering kali tidak mencukupi kebutuhan air konsumtif tanaman (Sukertayasa, 2017).

Beberapa faktor lain yang dapat menjelaskan perbedaan nilai ketersediaan air irigasi antara lokasi hulu, tengah dan hilir sepanjang saluran irigasi, yaitu:

a) Kondisi fisik jaringan dan kebiasaan petani menggunakan sistem pengairan mengalir dengan genangan yang cukup tinggi. Keadaan yang sama juga telah dikemukakan Farhan (2012) yaitu kehilangan air yang cukup besar terjadi akibat kurang berfungsinya pintu-pintu air dan petani memasukkan air ke petak tersier secara berlebihan,

b) Petugas pengatur pintu air belum efektif dalam mengatur pembagian air. Menurut Farhan (2012) pada daerah-daerah yang relatif basah pengaturan penggunaan air belum ketat dilakukan dan peranan lembaga pengatur/penggunaan air belum aktif. Kondisi tersebut hampir sama seperti di subak.

Rata-rata nilai ketersediaan air irigasi di saluran irigasi pada ketiga lokasi melebihi kebutuhan tanaman, terjadi dalam semua fase pertumbuhan tanaman. Penggunaan air irigasi pada petak tersier terus berlangsung selama air disaluran tersedia, walaupun pada saat curah hujan mencukupi kebutuhan tanaman. Penyadapan air irigasi pada saat curah hujan efektif mencukupi kebutuhan tanaman dengan tujuan untuk mendapatkan genangan air yang cukup tinggi. Kontribusi curah hujan efektif sangat besar dalam memasuk air untuk tanaman dan mengurangi jumlah kebutuhan air suatu tanaman terutama pada lokasi hilir saluran tersier. Secara umum curah hujan efektif dapat digunakan untuk menghemat penggunaan air irigasi. Apabila curah hujan efektif diperhitungkan dalam penyaluran air, maka penggunaan air irigasi dapat berjalan dengan efisien (Asri, 2014).

\section{RPM Irigasi pada Subak Daerah Hulu, Tengah dan Hilir}

Dari hasil pengukuran dan perhitungan rasio pretasi manajemen irigasi untuk budidaya tanaman padi di subak daerah hulu, tengah dan hilir dapat dilihat pada
Tabel 1. Rasio Prestasi Manajemen (RPM) irigasi digunakan untuk melihat perbandingan antara kebutuhan air irigasi riil dengan kebutuhan air irigasi sebenarnya. Dengan Rasio Prestasi Manajemen (RPM) diharapkan dapat mengetahui baik dan sangat kurangnya pemberian air irigasi pada saluran inlet. Apabila kebutuhan air irigasi sesuai dengan pemberian air irigasi maka dapat dikatakan RPM irigasi baik sedangkan jika kebutuhan air irigasi tidak sesuai dengan pemberian air irigasi misalnya air yang diberikan berlebih dan kurang maka dapat dikatakan RPM irigasi sangat kurang.

Tabel 1, menunjukan perbedaan RPM yang cukup besar antara daerah hulu, tengah dan hilir. Daerah hulu mempunyai RPM yang paling buruk diantara RPM daerah tengah dan hilir. Nilai RPM irigasi subak daerah hulu paling besar terjadi pada periode I yaitu 5.36 dengan klasifikasi RPM irigasinya sangat kurang. Untuk nilai RPM paling rendah terjadi pada periode VII yaitu 1.98 dengan klasifikasi sangat kurang. Terbukti selama periode masa tanam (I sampai VII) RPM daerah hulu selalu kelebihan air yang mengakibatkan RPM menjadi sangat kurang. Menurut (Farhan, 2012) kelebihan air disebabkan oleh kurang optimalnya pengelolaan irigasi, curah hujan yang tinggi dan kebiasaan petani yang kurang efisien dalam menggunakan air untuk kebutuhan irigasi.

Untuk RPM irigasi daerah tengah selama periode masa tanam lebih baik dibandingkan RPM irigasi daerah hulu. Nilai RPM irigasi yang paling besar terjadi pada periode I yaitu 2.73 dan terendah periode VII yaitu 1.03. Selama periode I sampai V RPM irigasinya sangat kurang ini disebabkan oleh kelebihan air irigasi. Kelebihan air irigasi ini disebabkan oleh curah hujan yang cukup tinggi dan masalah dipenyaluran irigasi di periode I sampai $\mathrm{V}$ di daerah tengah. Berdasarkan hasil perhitungan curah hujan efektif didapat pada periode I sampai $\mathrm{V}$ adalah $6.19 \mathrm{~mm} / \mathrm{hari}$. Menurut Nugroho (2007) Beberapa masalah yang timbul pada penyaluran irigasi adalah ketidaksesuaian penyaluran air ke daerah irigasi yang dapat menimbulkan kurang efisien dalam pendistribuasian air irigasi. Periode VI memiliki klasifikasi RPM yang kurang sedangkan untuk periode VII memiliki klasifikasi RPM irigasi yang baik ini disebabkan pintu air yang di subak daerah tengah sudah mulai ditutup setengah oleh petani karena tanaman padi periode tahap pemasakan sedikit membutuhkan air irigasi sehingga terjadilah kesesuaian pemberian air irigasi terhadap kebutuhan air irigasi. Untuk daerah hilir RPM irigasinya paling baik dibandingkan daerah tengah dan hulu. Nilai RPM irigasi daerah hilir paling tinggi terjadi pada periode I dan II yaitu 2.43 dan terendah terjadi pada periode $\mathrm{V}$ yaitu 0.85 . Untuk RPM irigasi pada periode 
I sampai III sangat kurang disebabkan oleh kelebihan air irigasi. Kelebihan air irigasi ini disebabkan curah hujan yang cukup tinggi pada periode I sampai III. Berdasarkan hasil perhitungan curah hujan efektif didapat $5.96 \mathrm{~mm} /$ hari selama periode I sampai III. Sedangkan untuk periode IV sampai VII kondisi ketersediaan air daerah hilir yang cukup untuk memenuhi kebutuhan air irigasi sehingga klasifikasi RPM irigasinya baik.

Tabel 1. Rasio Prestasi Manajemen Irigasi Untuk Budidaya Tanaman Padi Daerah Subak Hulu, Tengah dan Hilir Subak Kabupaten Tabanan

\begin{tabular}{|c|c|c|c|c|c|}
\hline Daerah Subak & $\begin{array}{c}\text { Periode } \\
\text { (1/2 Bulan) }\end{array}$ & $\begin{array}{c}\text { KAI } \\
\text { (lt/dt/ha) }\end{array}$ & $\begin{array}{c}\text { Debit } \\
\text { Tersedia } \\
\text { (lt/dt/ha) }\end{array}$ & Rasio Qt \& Qr & RPM \\
\hline \multirow{7}{*}{ Hulu } & I & 0.33 & 1.77 & 5.36 & Sangat Kurang \\
\hline & II & 0.38 & 1.47 & 3.87 & Sangat Kurang \\
\hline & III & 0.51 & 1.51 & 2.96 & Sangat Kurang \\
\hline & IV & 0.57 & 1.47 & 2.58 & Sangat Kurang \\
\hline & $\mathrm{V}$ & 0.55 & 1.78 & 3.24 & Sangat Kurang \\
\hline & VI & 0.49 & 1.7 & 3.47 & Sangat Kurang \\
\hline & VII & 0.6 & 1.19 & 1.98 & Sangat Kurang \\
\hline \multirow{7}{*}{ Tengah } & $\mathrm{I}$ & 0.43 & 1.49 & 3.47 & Sangat Kurang \\
\hline & II & 0.44 & 1.2 & 2.73 & Sangat Kurang \\
\hline & III & 0.54 & 1.25 & 2.31 & Sangat Kurang \\
\hline & IV & 0.59 & 1.08 & 1.83 & Sangat Kurang \\
\hline & $\mathrm{V}$ & 0.54 & 1.16 & 2.15 & Sangat Kurang \\
\hline & VI & 0.7 & 1.09 & 1.56 & Kurang \\
\hline & VII & 0.97 & 1 & 1.03 & Baik \\
\hline \multirow{7}{*}{ Hilir } & I & 0.47 & 1.14 & 2.43 & Sangat Kurang \\
\hline & II & 0.46 & 1.12 & 2.43 & Sangat Kurang \\
\hline & III & 0.53 & 1.01 & 1.91 & Sangat Kurang \\
\hline & IV & 0.93 & 0.95 & 1.02 & Baik \\
\hline & $\mathrm{V}$ & 1.09 & 0.93 & 0.85 & Baik \\
\hline & VI & 1.01 & 0.89 & 0.88 & Baik \\
\hline & VII & 0.93 & 0.87 & 0.94 & Baik \\
\hline
\end{tabular}

\section{KESIMPULAN DAN SARAN}

\section{Kesimpulan}

Berdasarkan hasil penelitian dapat disimpulkan bahwa:

Kebutuhan air irigasi untuk budidaya tanaman padi berbeda-beda pada masing-masing daerah subak hulu, tengah dan hilir. Kebutuhan air irigasi subak daerah hulu terbesar terjadi di periode VII yaitu 0.6 lt/dt dan terkecil di periode I yaitu $0.33 \mathrm{lt} / \mathrm{dt} / \mathrm{ha}$. Kebutuhan air irigasi daerah tengah terbesar di periode VII yaitu $0.97 \mathrm{lt} / \mathrm{dt} / \mathrm{ha}$ dan terkecil di periode I yaitu $0.43 \mathrm{lt} / \mathrm{dt} / \mathrm{ha}$. Kebutuhan air irigasi daerah hilir terbesar di periode $\mathrm{V}$ yaitu $1.09 \mathrm{lt} / \mathrm{dt} / \mathrm{ha}$ dan terkecil pada periode I yaitu $0.47 \mathrm{lt} / \mathrm{dt} / \mathrm{ha}$.

Ketersediaan air irigasi untuk budidaya tanaman padi masing-masing subak daerah hulu, tengah dan hilir berbeda-beda. Debit tersedia subak daerah hulu paling besar rata-rata dari periode I sampai VII adalah $1.56 \mathrm{lt} / \mathrm{dt} / \mathrm{ha}$ dan untuk debit rata-rata tersedia daerah tengah dari periode I sampai VII lebih rendah dari daerah hulu yaitu $1.18 \mathrm{lt} / \mathrm{dt} / \mathrm{ha}$ sedangkan untuk debit rata-rata tersedia daerah hilir dari periode I sampai VII paling rendah yaitu $0.98 \mathrm{lt} / \mathrm{dt} / \mathrm{ha}$.

Rasio Prestasi Manajemen (RPM) irigasi untuk budidaya tanaman padi di masing-masing daerah 
subak hulu, tengah dan hilir. RPM daerah hulu dari periode I sampai VII dikategorikan sangat kurang dan untuk daerah tengah RPM irigasi dari periode I sampai V dikategorikan sangat kurang, periode VI dengan kategori kurang, periode VII kategori baik sedangkan untuk subak daerah hilir dari periode I sampai III dikategorikan sangat kurang dan periode IV sampai VII dikategorikan baik.

\section{Saran}

Berdasarkan hasil penelitian ini disarankan:

Rasio Prestasi Manajemen (RPM) irigasi yang sangat kurang itu sebaiknya diatur dalam pemberian air irigasi yang sesuai dengan kebutuhan air tanaman. Misalnya curah hujan yang tinggi pada suatu daerah hulu dan banyak yang mampu diserap oleh tumbuhan sehingga kebutuhan air tanaman sedikit sebaiknya di pintu air ditutup setengah sehingga tidak semuanya air yang masuk ke tanaman dan itulah yang menyebabkan pemberian air yang melimpah yang mengakibatkan efisiensi pengairan belum optimal.

Perlu adanya sosialisasi tentang pengetahuan kebutuhan air tanaman dan ketersediaan air tanaman sehingga petani bisa memakai air irigasi secara efisiensi jika air yang terlalu berlebih atau kurang di areal sawah akan berdampak buruk bagi tanaman sedangkan jika kebutuhan air tanaman sesuai dengan pemberian air ini akan dapat merangsang tanaman sehingga tumbuh kembang tanaman menjadi optimal.

\section{DAFTAR PUSTAKA}

Anonim. (2011). Standar Perencanaan Irigasi. Kriteria Perencanaan (KP-01, KP- 07). Direktorat Jenderal Pengairan.

Asri, A., Kusuma, Z., \& Suprayogo, D. (2014). Kajian Faktor Penentu Sosio-Kultural dan Kinerja Sistem Irigasi (Studi Kasus Audit Irigasi Daerah Irigasi (DI) Molek Kepanjen Kab. Malang). HABITAT, 25(1), 40-48.

Farhan, A. (2012). Kinerja Pendistribusian Air Irigasi di Daerah Hulu, Tengah, dan Hilir. Banda Aceh: Universitas Syah Kuala.

Heryani, N., Balitklimat, B. B. S. D. L. P., Balitbangtan, K., Kartiwa, B., Balitklimat, B., Hamdani, A \& Balitklimat, B. (2017). Analisis Ketersediaan dan Kebutuhan Air Irigasi pada Lahan Sawah: Studi Kasus di Provinsi Sulawesi Selatan.

Jannata, J., Abdullah, S. H., \& Priyati, A. (2015). Analisa Kinerja Pengelolaan Irigasi Di Daerah Irigasi Lemor, Kabupaten Lombok Timur, Nusa Tenggara Barat. Jurnal Ilmiah Rekayasa Pertanian dan Biosistem, 3(1), 112-121.

Kalsim, D. (2006). Kebutuhan Air Irigasi [diktat matakuliah irigasi dan draninase. Bogor:
Institut Pertanian Bogor.

Kusumowarno, S. (2014). Percepatan peningkatan produksi dan produktivitas padi di lahan rawa berkelanjutan dan lestari. In Prosiding Seminar Nasional "Inovasi Teknologi Pertanian Spesifik Lokasi”. Bogor.

Nugroho, P. S., \& Pamuji, P. (2007). Evaluasi Kinerja Jaringan Irigasi Banjaran Untuk Meningkatkan Efektifitas Dan Efisiensi Pengelolaan Air Irigasi.

Subagyono, K., Dariah, A., Surmaini, E., \& Kurnia, U. (2010). Pengelolaan air pada tanah

Sawah. Diakses dari: http://balittanah. litbang. deptan. go.

id/dokumentasi/buku/tanahsawah/tanahs awah7.

Sugeng, P. (2015). Efisiensi irigasi, [diktat matakuliah irigasi dan draninase. Bogor: Institut Pertanian Bogor.

Sukertayasa, I. P., \& Wijaya, I. M. A. S. \& Tika, I. W. Analisis Efisiensi Penggunaan Air Irigasi pada Subak Agung Yeh Sungi. Jurnal BETA (Biosistem dan Teknik Pertanian), 5(1), 45-50.

Takeda, K., \& Sosrodarsono, S. (2003). Hidrologi untuk Pengairan. Editor Sosrodarsono, S. PT Pradnya Paramita: Jakarta.

Vegara, B. S., \& et al. (2002). Bertanam Padi Sawah. Swadaya, Jakarta.

Viessman. (2001). Introduction to Hydrology (2nd ed.). New York: Harper and Row Publishers.

Windia, Sudarta, W. W., \& Astiti, W. S. (2015). Sistem Subak di Bali (Kajian Sosiologis). Denpasar: Universitas Udayana Press. 